\title{
Fetomaternal outcome in COVID-19 infected pregnant women: a preliminary clinical study
}

\author{
Parul T. Shah, Sapana R. Shah, Sushma R. Shah, Pushpa A. Yadav, Babulal S. Patel, \\ Tanmay J. Chudasama*
}

Department of Obstetrics and Gynecology, SVP Hospital, NHL Municipal Medical College, Ahmedabad, Gujarat, India

Received: 22 June 2020

Accepted: 31 July 2020

*Correspondence:

Dr. Tanmay J. Chudasama,

E-mail: tanmayjc@gmail.com

Copyright: () the author(s), publisher and licensee Medip Academy. This is an open-access article distributed under the terms of the Creative Commons Attribution Non-Commercial License, which permits unrestricted non-commercial use, distribution, and reproduction in any medium, provided the original work is properly cited.

\section{ABSTRACT}

Background: WHO has declared COVID-19 infection a health emergency of international concern on $11^{\text {th }}$ March, 2020. It is not clear whether clinical characteristics of pregnant women with COVID-19 differ from those of nonpregnant women and whether it aggravates COVID-19 symptoms and whether antiviral therapy is necessary for COVID-19 infected pregnant women.

Methods: This is prospective study of 125 cases based on the compiled clinical data for pregnant women with COVID-19 between $15^{\text {th }}$ April 2020 and $10^{\text {th }}$ June 2020. A laboratory confirmed positive case of COVID-19 infection in pregnant women were included.

Results: The most common symptoms at presentation were cough in $61.6 \%(77 / 125)$ and fever in $46.4 \%(58 / 125)$. Other reported symptoms were sore throat in $13.6 \%$ (17/125), myalgia in $10.4 \%(13 / 125)$ while $38.4 \%$ (48/125) were asymptomatic. There were total 97 deliveries (including 2 twins' deliveries) among which 3 cases had IUD. Present study reported 96 live births. The incidence of missed abortion was 2.4\% (3/125). The incidence of preterm birth before 37 weeks was $8.2 \%$ (8/97). Ninety-six (96.9\%) of neonates were tested for SARS-CoV-2 viral nucleic acid on nasopharyngeal and pharyngeal samples and $16.67 \%$ (16/96) were resulted positive.

Conclusions: At present, there is no evidence regarding the greater risk of pregnant women to succumb to COVID-19 infection and experience severe pneumonia. The risks of spontaneous abortion and preterm birth are not increased as reported in this study but shows possibility of vertical transmission when it manifests during the third trimester of pregnancy.

Keywords: COVID-19, Maternal morbidity, Pneumonia, Pregnancy, SARS-CoV-2

\section{INTRODUCTION}

On March 11, 2020 World Health Organization (WHO) declared corona virus disease (COVID-19) a public health emergency of international concern since its outbreak in Wuhan, China. ${ }^{1}$ Coronaviruses are enveloped RNA viruses that are distributed widely among humans, other mammals and birds and they cause respiratory, neurologic, hepatic and enteric diseases. ${ }^{2,3}$ Six coronavirus species are known to cause human disease and four of them - 229E, OC43, NL63, and HKU1 are less pathogenic causing common cold symptoms in immunocompetent individuals. ${ }^{4}$ The two other strains severe acute respiratory syndrome coronavirus (SARS$\mathrm{CoV}$ ) and Middle East respiratory syndrome coronavirus (MERS-CoV) - are zoonotic in origin and sometimes causes fatal illness. ${ }^{5}$ Due the its high prevalence and wide distribution, the large genetic diversity and frequent genetic recombination, and increasing human-animal interface activities, novel coronaviruses emerge periodically in humans owing to frequent cross-species infections. ${ }^{5}$ There is $82 \%$ homology between the genome 
of the virus that causes COVID-19 infection, severe acute respiratory syndrome coronavirus 2 (SARS-CoV-2) and human severe acute respiratory syndrome coronavirus (SARS-CoV). ${ }^{6}$

There have been extensive studies on the HRCT and clinical manifestations of patients with COVID-19 infection and treatment monitoring but studies of pregnant women with COVID-19 infection remains relatively rare. Still it is doubtful whether clinical characteristics of pregnant women with COVID-19 infection differ from those of nonpregnant women with COVID-19 infection and pregnant women with SARS$\mathrm{CoV}$, whether pregnancy and labour aggravate COVID19 symptoms and whether antiviral therapy is essential for COVID-19 affected pregnant women.

According to the guidelines from the Royal College of obstetricians and gynaecologists (RCOG), pregnant women do not appear more likely to contract the COVID19 infection than the general population. ${ }^{3}$ The centres for disease control and prevention (CDC) report that pregnant women manifest a more severe illness when infected with viruses from the same family as the SARS CoV-2 virus and from other respiratory tract viruses such as the influenza virus. ${ }^{8}$ This depicts that once the coronavirus has been infected this can theoretically lead to more severe symptoms than not, since it is known that in pregnant women there is alteration of the immune system and response to viral infections. These findings of increased severity of clinical manifestations in pregnancy are more prominent towards the end of pregnancy. Hence, there is a possibility that pregnant women infected with COVID-19 may potentially develop more severe symptoms such as pneumonia and marked hypoxia, similar to people who are elderly, immunosuppressed or have existing morbidity such as diabetes, cancer or chronic lung disease. The RCOG guidelines have contrastingly reported that the absolute risk of this is low. ${ }^{7}$

The purpose of this study was to describe the clinical manifestations and fetomaternal outcome of pregnant women infected with COVID-19, monitor for changes before and after delivery, and provide some initial evidence for guiding the management of pregnant women with COVID-19 infection.

\section{METHODS}

This preliminary study is prospective study of 125 cases based on compiled clinical and outcome data for pregnant women infected with COVID-19 between $15^{\text {th }}$ April 2020 and $10^{\text {th }}$ June 2020 at a tertiary level hospital. A laboratory confirmed case of COVID-19 is defined as a positive result by quantitative reverse transcriptase polymerase chain reaction (qRT-PCR) assay of maternal pharyngeal and nasopharyngeal swab specimens. All the mandatory safety precautional measures- personal protective equipment (PPE) including jumpsuit, gloves,
N-95 mask, splash resistant face shield, goggles were used by all the health care professionals in labour wards and operation theatres. Separate premises were assigned as donning and doffing areas.

\section{Inclusion criteria}

A laboratory confirmed positive case of COVID-19 infection in pregnant women were included in this study.

\section{Exclusion criteria}

Pregnancy with clinical signs and symptoms similar to SARS-CoV-2 but nasopharyngeal and pharyngeal swab were reported negative were excluded from this study.

Complete epidemiologic history, obstetric history, clinical symptoms, signs, specific obstetric condition, laboratory and radiologic investigations, treatment measures, complications and outcome data were collected from electronic medical records software ARCUS and curated within customized data collection format. All laboratory investigations and radiologic assessments were performed according to the clinical care needs of the present pregnancy. Laboratory investigations included complete blood cell count (CBC), liver function test (LFT), renal function test (RFT), C-reactive protein (CRP), serum lactate dehydrogenase (LDH), thyroid function test (TFT) and HbA1C. Data on pregnancy and neonatal outcome, including gestational age at delivery, mode of delivery, indication for cesarean delivery, complications, neonatal birthweight and neonatal intensive care unit (NICU) admission were analyzed. The date of data cut-off for outcomes was $10^{\text {th }}$ June 2020 . Neonatal pharyngeal and nasopharyngeal swab samples were collected immediately after delivery in the NICU and tested for SARS-CoV-2 using qRT-PCR. Sample collection, processing, and laboratory testing were complied with WHO guidance. ${ }^{9}$

Data were compiled, tabulated, analyzed, interpreted by the authors. All the authors involved in the study reviewed the manuscript and vouched for the accuracy and completeness of the data.

\section{RESULTS}

The characteristics and outcomes of the study population of 125 laboratory confirmed COVID-19 positive cases are demonstrated in Table 1. The mean age was 25.2 (range 18-40) years with $73.6 \%$ cases between age of 21 30 years. In $31.2 \%(39 / 125)$ cases contact history was present with infected persons. The most common symptoms at presentation were cough in $61.6 \%(77 / 125)$ and fever in $46.4 \%(58 / 125)$. Other reported symptoms were sore throat in $13.6 \%(17 / 125)$, myalgia or arthralgia in $10.4 \%(13 / 125)$, dyspnoea in $8 \%(10 / 125)$ while $38.4 \%$ $(48 / 125)$ of cases were asymptomatic. All these cases underwent necessary laboratory and radiological investigations and detailed epidemiologic history. 
Table 1: Demographics, clinical characteristics and clinical outcomes of COVID-19 infection in pregnant women.

\begin{tabular}{|c|c|}
\hline Clinical characteristics & $\begin{array}{l}\text { Number of } \\
\text { patients } \mathbf{N}(\%)\end{array}$ \\
\hline \multicolumn{2}{|l|}{ Age group (years) } \\
\hline$\leq 20$ & $13(10.4)$ \\
\hline $21-30$ & $92(73.6)$ \\
\hline$>30$ & $20(16)$ \\
\hline \multicolumn{2}{|l|}{ Obstetric status on admission } \\
\hline Antenatal & $67(53.6)$ \\
\hline Postnatal & $55(44)$ \\
\hline Aborted & $3(2.4)$ \\
\hline \multicolumn{2}{|c|}{ Gestational age of antenatal cases on admission } \\
\hline$\leq 13$ weeks & $10(14.9)$ \\
\hline 14-28 weeks & $12(17.9)$ \\
\hline 28-40 weeks & $39(58.2)$ \\
\hline$\geq 40$ weeks & $6(8.9)$ \\
\hline \multicolumn{2}{|l|}{ Gravidity } \\
\hline Primigravida & $27(21.6)$ \\
\hline Multigravida & $98(78.4)$ \\
\hline \multicolumn{2}{|l|}{ Contact with infected person } \\
\hline Yes & $39(31.2)$ \\
\hline No & $86(68.8)$ \\
\hline \multicolumn{2}{|c|}{ Covid-19 related clinical features } \\
\hline Cough & $77(61.6)$ \\
\hline Fever & $58(46.4)$ \\
\hline Sore throat & $17(13.6)$ \\
\hline Myalgia or arthralgia & $13(10.4)$ \\
\hline Dyspnoea & $10(8)$ \\
\hline Diarrhoea & $4(3.2)$ \\
\hline No symptoms & $48(38.4)$ \\
\hline \multicolumn{2}{|l|}{ Pregnancy associated with } \\
\hline Gestational diabetes mellitus & $6(4.8)$ \\
\hline Gestational hypertension & $7(5.6)$ \\
\hline Preeclampsia & $2(1.6)$ \\
\hline \multicolumn{2}{|l|}{ Treatment } \\
\hline Antibiotic therapy & $125(100)$ \\
\hline Antiviral therapy & $0(0.0)$ \\
\hline Multivitamins containing zinc & $125(100)$ \\
\hline Tablet vitamin C & $125(100)$ \\
\hline Use of corticosteroids & $30(24)$ \\
\hline Hydroxychloroquine & $19(15.2)$ \\
\hline ICU admission & $3(2.4)$ \\
\hline Tocilizumab & $0(0.0)$ \\
\hline \multicolumn{2}{|l|}{ Clinical outcome } \\
\hline $\begin{array}{l}\text { Discharged after double } \\
\text { negative swab report }\end{array}$ & $17(13.6)$ \\
\hline $\begin{array}{l}\text { Remained asymptomatic and } \\
\text { discharged (as per revised } \\
\text { discharge policy by MoHWF }{ }^{10} \text { ) }\end{array}$ & $89(71.2)$ \\
\hline Remained in ward & $19(15.2)$ \\
\hline Died & $0(0.0)$ \\
\hline
\end{tabular}

Table 2: Laboratory and radiologic findings.

\begin{tabular}{|c|c|}
\hline $\begin{array}{l}\text { Laboratory and radiological } \\
\text { investigations }\end{array}$ & $\begin{array}{l}\text { Number of } \\
\text { patients }(\mathbf{N}) \%\end{array}$ \\
\hline \multicolumn{2}{|c|}{ Leucocytes (normal range: 4 to $11 \mathrm{kU} / \mathrm{l}$ ) } \\
\hline Decreased & $0(0.0)$ \\
\hline Normal & $86(68.8)$ \\
\hline Increased & $39(31.2)$ \\
\hline \multicolumn{2}{|c|}{ Neutrophil/Lymphocyte ratio (NLR) (normal: 1-3) } \\
\hline Normal & $36(28.8)$ \\
\hline Increased & $89(71.2)$ \\
\hline \multicolumn{2}{|c|}{ C-reactive protein (normal range: $<0.6 \mathrm{mg} / \mathrm{dL}$ ) } \\
\hline Positive & $80(64)$ \\
\hline Negative & $45(36)$ \\
\hline \multicolumn{2}{|c|}{$\begin{array}{l}\text { Serum lactate dehydrogenase }(\mathrm{LDH}) \text { (normal } \\
\text { range: } 140-280 \mathrm{U} / \mathrm{L})\end{array}$} \\
\hline Normal & $81(64.8)$ \\
\hline Increased & $44(35.2)$ \\
\hline \multicolumn{2}{|c|}{ SGPT/SGOT (normal range: 5-40 U/L) } \\
\hline Normal & $80(64)$ \\
\hline Elevated & $45(36)$ \\
\hline \multicolumn{2}{|c|}{ Chest $\mathrm{X}$-ray findings (in 85 cases) } \\
\hline No abnormality & $66(77.6)$ \\
\hline Pleural effusion & $1(1.17)$ \\
\hline $\begin{array}{l}\text { Patchy haziness/ changes of } \\
\text { pneumonia }\end{array}$ & $18(21.2)$ \\
\hline
\end{tabular}

Out of 125 cases on admission, 53.6\% (67/125) cases were antenatal and $44 \%(55 / 125)$ cases were postnatal women which were delivered at other allied corporation hospitals and transferred to our COVID dedicated institute, $2.4 \%(3 / 125)$ had missed abortion. The pregnancy was in first trimester in $14.9 \%(10 / 67)$, second trimester in $17.9 \%(12 / 67)$, third trimester in $58.2 \%$ $(39 / 67)$ and post term in $8.9 \%(6 / 67)$ cases. All the fullterm pregnant women were motivated, counselled, explained the daily fetal movement counting (DFMC), undergone USG foetus including fetal doppler study on admission and fetal surveillance was done by non-stress test (NST) twice a week.

In this study, there were 6 cases $(4.8 \%)$ with gestational diabetes and 7 cases $(5.6 \%)$ with gestational hypertension and 2 cases $(1.6 \%)$ with preeclampsia including 1 case $(0.8 \%)$ of HELLP syndrome and these pregnancy complications were unrelated to COVID-19 infection. There were 19 patients $(15.2 \%)$ with mild pneumonia who were shifted on oxygen bed and oxygen saturation (SPO2) was monitored. These 19 patients were treated with Injection methyl-prednisone and tablet hydroxychloroquine $400 \mathrm{mg} 12$ hourly loading dose on day 1 followed by $200 \mathrm{mg} 12$ hourly for next 4 days and improvement in symptoms was noted. All these 19 patients were postnatal and tablet hydroxychloroquine has not been given to any antenatal patients due to its potential teratogenicity. Antibiotics and supportive multivitamins including vitamin $\mathrm{C}$ were given in all the 125 patients. Steroids was administered in $24 \%(30 / 125)$ 
cases. Three patients required ICU admission (1 severe pneumonia, 1 HELLP syndrome, 1 severe preeclampsia). A total of $106(84.8 \%)$ cases had been discharged and there was no maternal death.

On admission, total leucocyte count (TLC) was increased in $31.2 \%(39 / 125)$ of the patients and neutrophil/lymphocyte ratio (NLR) was elevated in $71.2 \%(89 / 125)$ of patients. Elevated levels of C-reactive protein were found in $64 \%$ of the patients. In view of increased TLC, injection methyl-prednisone was administered alongside monitoring blood sugar level and found to be very effective in controlling the inflammation. Patients with severe disease had more prominent laboratory abnormalities than those with mild disease. In the 85 cases that underwent chest X-ray (antenatal patients with lead shield) at the time of admission, 22.3\% (19/85) revealed abnormal results (1 bilateral pleural effusion and 18 showed patchy haziness and peripheral opacities). Liver enzymes - SGPT/SGOT were elevated in $36 \%(45 / 125)$ patients and $35.2 \%$ (44/125) reported increased serum levels of LDH

\section{Pregnancy outcomes}

Of the 125 cases, 3 cases $(2.4 \%)$ had missed abortion at 10 weeks, 14 weeks and 18 weeks (retained placental tissue) respectively and dilatation and evacuation (D and E) was performed in these cases. The one case with 14 weeks abortion was complicated with uterine perforation during $\mathrm{D}$ and $\mathrm{E}$ (performed outside) and required emergency laparotomy. Ectopic pregnancy was reported in $2(1.6 \%)$ cases out of which 1 case of 10 weeks cornual ectopic was managed by emergency laparotomy and salpingectomy performed and 1 case of chronic ectopic $(3 \times 3 \mathrm{~cm} \mathrm{G}-\mathrm{sac})$ managed conservatively.

Table 3: Pregnancy outcomes of COVID-19 disease.

\begin{tabular}{|c|c|c|c|}
\hline \multicolumn{2}{|l|}{ Outcome } & \multicolumn{2}{|c|}{$\begin{array}{l}\text { Number of patients } \\
\mathbf{N}(\%)\end{array}$} \\
\hline \multicolumn{4}{|c|}{ Fate of pregnancy } \\
\hline \multicolumn{2}{|c|}{ Missed abortion } & \multicolumn{2}{|l|}{$3(2.4)$} \\
\hline \multicolumn{2}{|c|}{ Ectopic pregnancy } & \multicolumn{2}{|l|}{$2(1.6)$} \\
\hline \multicolumn{2}{|l|}{ IUD } & \multicolumn{2}{|l|}{$3(2.4)$} \\
\hline \multicolumn{2}{|l|}{ Live birth } & \multicolumn{2}{|l|}{$94(75.2)$} \\
\hline \multicolumn{2}{|c|}{ Continuance of pregnancy } & $23(18.4)$ & \\
\hline \multicolumn{4}{|c|}{ Mode of delivery (total deliveries = 97) } \\
\hline \multirow{2}{*}{$\begin{array}{l}\text { Caesarean } \\
\text { delivery }\end{array}$} & Live & \multirow{2}{*}{$52(53.6)$} & $51(52.5)$ \\
\hline & IUD & & $1(1.03)$ \\
\hline \multicolumn{2}{|c|}{ Normal delivery } & \multicolumn{2}{|l|}{$40(41.2)$} \\
\hline \multicolumn{2}{|c|}{ Preterm vaginal delivery } & \multicolumn{2}{|l|}{$2(2.06)$} \\
\hline \multirow{2}{*}{ Hysterotomy } & Live & \multirow{2}{*}{$3(3.1)$} & $2(2.06)$ \\
\hline & IUD & & $1(1.03)$ \\
\hline
\end{tabular}

A total of 97 pregnant women including 2 twins delivered their babies of whom $53.6 \%$ (52/97) underwent caesarean delivery, $3.1 \%$ (3/97) required hysterotomy and $43.26 \%$ (42/97) had vaginal delivery including 2 preterm vaginal delivery at 28 weeks and 32 weeks. Caesarean delivery was indicated for previous caesarean delivery in COVID19 infection in $36.5 \%$ (19/52), prolonged first stage in $9.6 \%(5 / 52)$, induction failure in $5.7 \%(3 / 52)$, postdate pregnancy in $5.7 \%$ (3/52), abnormal fetal doppler in $3.8 \%$ $(2 / 52)$, arrest in 2 nd stage of labour in $3.8 \%(2 / 52)$, severe preeclampsia in $1.9 \%(1 / 52)$, placenta previa in $1.9 \%(1 / 52)$, and abruption in $1.9 \%(1 / 52)$. The incidence of preterm delivery was $3.1 \%$ (3/97) before 28 weeks, $3.1 \%(3 / 97)$ cases between 28 weeks and 34 weeks and it was $2.03 \%(2 / 97)$ between 34 weeks and 37 weeks gestation. Among the 8 preterm deliveries, there were 3 hysterotomies ( 1 for IUFD with failed induction of labour, 2 for abnormal fetal doppler with previous $2 \mathrm{CS}$ ), 3 caesarean sections ( 1 for abruption and 1 for bad obstetric history and 1 for prev2cs+ threatened rupture) and 2 were preterm vaginal delivery at 28 weeks and 32 weeks respectively. There were no cases with spontaneous onset of labour. The incidence of preterm birth before 37 weeks was therefore $8.2 \%$ (8/97). There were no cases of spontaneous preterm delivery before 34 weeks.

Table 4: Neonatal outcomes of COVID-19 deliveries.

\begin{tabular}{|ll|}
\hline Outcome & $\begin{array}{l}\text { Number of patients } \mathbf{N} \\
(\%) \text { (Total neonates: 99) }\end{array}$ \\
\hline $\begin{array}{l}\text { Live (including } \mathbf{2} \text { twins' } \\
\text { delivery) }\end{array}$ & $96(96.9)$ \\
\hline $\begin{array}{l}\text { Live and infected with } \\
\text { COVID-19 }\end{array}$ & $16(16.1)$ \\
\hline Live and non-infected & $80(80.8)$ \\
\hline Neonatal deaths & $2(2.02)$ \\
\hline Still born & $0(0.0)$ \\
\hline Intrauterine fetal death & $3(3.03)$ \\
\hline
\end{tabular}

In the remaining 23 ongoing pregnancy, USG foetus revealed normal fetal growth and normal doppler study with 1 patient with twins, 2 with precious pregnancy and 1 with breech and none showing fetal growth restriction (FGR) till cut-off date $10^{\text {th }}$ June 2020 . There is 1 patient with gestational diabetes mellitus and hypertension and the other 22 patients with no fetal or maternal complications reported as of $10^{\text {th }}$ June 2020 .

There were total 97 deliveries in this study including 2 twins' deliveries among which 3 were IUD (96 live born and 3 IUD deliveries). All the 96 live born neonates were admitted to the NICU for further treatment and to rule out COVID-19 infection. There were 2 neonatal deaths. Both of them were delivered at 27 weeks maturity as during antenatal scan, fetal doppler study reported reverse end diastolic flow with severe utero-placental insufficiency. Both of these neonates were $<1 \mathrm{~kg}$ and were treated with invasive ventilation in view of severe neonatal asphyxia and died within 12 hours of birth. There were $96.9 \%$ $(96 / 99)$ of neonates who underwent testing for SARSCoV-2 viral nucleic acid on nasopharyngeal and 
pharyngeal swab samples and the results were positive in $16.67 \%(16 / 96)$.

\section{DISCUSSION}

In this preliminary study of 125 cases, authors observed that the clinical characteristics of the women with COVID-19 infection during pregnancy were similar to those of nonpregnant adults with COVID-19 infection comparable with studies by Guan et al and Wu et al. ${ }^{11,12}$ Till date, summarized data from 125 cases, with a total of 23 women with ongoing pregnancy, indicated that the most common symptoms at presentation were cough $(61.6 \%)$ and fever (46.4\%); $48(38.4 \%)$ of pregnant patients did not present with symptoms, but most of these patients were diagnosed as having COVID-19 infection by intensive field testing and contact tracing during the initial phase of outbreak in India. FOGSI guidelines recommends that pregnant women residing in containment areas or in large migration gatherings/evacuees centre from hotspot districts presenting in labour or likely to deliver in next 5 days should be tested even if asymptomatic. ${ }^{13}$ Out of 125 cases, two-third of the patients had lymphopenia (increased NLR) and increased C-reactive protein, and 52\% (65 cases) showed patchy haziness and peripheral opacities on chest radiograph. Authors had reported clinical, laboratory, and radiologic characteristics that are similar to published pregnant and nonpregnant cases of COVID-19 infection. ${ }^{11,12}$

In normal pregnancy there is physiological activation of the innate limb of the immune response but study by Nacaasha et al reported that pregnant women with acute infection display a more aggressive immune respone. ${ }^{14}$ In present study, 7 of $125(5.6 \%)$ pregnant women experienced severe COVID-19 infection, which is in significantly lower to the $15.6 \%$ of severe disease that has been reported in studies from China. ${ }^{11,12}$ This finding are encouraging and can be attributed to our proactive and aggressive management of diagnosed pregnant cases to minimize the risk of disease progression. Elderly population, immunosuppressed and having comorbidities like diabetes, cancer, chronic lung disease is at greater risk of having severe disease with COVID-19 infection. ICU admission was required in $2.4 \%$ (3/125) of patients in view of severe pneumonia and preeclampsia and none died as of $10^{\text {th }}$ June 2020. Immunomodulators like IL-6 inhibitors - tocilizumab has been used for treating selected cases of severe pneumonia in ICU admitted patients in study institute but has not been administered in any of the 125 cases in this study. Study by Alattar et al reported that use of tocilizumab in patients with severe COVID-19 was associated with dramatic decline in inflammatory markers, radiological improvement and reduced ventilatory support requirements. ${ }^{15}$ There was a lack of clarity at the beginning of this outbreak and authors could only base our practice on past experience with SARS-CoV. As authors came across a greater number of COVID-19 cases, authors adapted our management, and care was provided by a multidisciplinary team.

It has been reported that viral pneumonia in pregnant women is associated with an increased risk of preterm birth, fetal growth restriction (FGR), and perinatal mortality by Madinger et al. ${ }^{16}$ It is reported by Chen et al that pregnant patients infected with viral pneumonia other than SARS-CoV-2 have increased risk of fetal growth restriction (FGR), preterm delivery, low birthweight and Apgar score $<7$ at 5 minutes.17A case series of 12 COVID-19 infected pregnant women in Hong Kong reported 3 maternal deaths; 4 of 7 patients $(57 \%)$ had spontaneous abortion in first trimester, 4 of 5 patients $(80 \%)$ had preterm birth, and 2 pregnant women recovered but their ongoing pregnancies were complicated by FGR. ${ }^{18}$ In 23 ongoing pregnancy in present study, none of them reported FGR till cut-off date $10^{\text {th }}$ June 2020.

It is reported from this study that the risk of spontaneous abortion is not increased in pregnant women infected with SARS-CoV-2 from the background risk of the healthy pregnant women. ${ }^{19}$ This study also suggests that although the risk of any preterm birth before 37 weeks' gestation is increased, COVID-19 is not associated with an increased risk of spontaneous preterm birth before 37 weeks. There were 8 cases of preterm birth ( 3 by cesarean delivery, 3 by hysterotomy and 2 preterm vaginal delivery) due to obstetric indication.

RCOG, in consultation with the $\mathrm{RCPCH}$, have provided guidance for delivery and neonatal care, which recommends that mode of delivery be determined primarily by obstetric indication, and recommends against routine separation of COVID-19-affected mothers and their babies. $^{7}$ Ninety-six $(96.9 \%)$ of neonates were tested for SARS-CoV-2 viral nucleic acid on nasopharyngeal and pharyngeal samples and $16.67 \%$ (16/96) were resulted positive.

One of the main purposes of this study was to look for the possibility of vertical transmission of SARS-CoV-2 infection. Authors could only evaluate neonatal nasopharyngeal and pharyngeal swab samples at birth to ascertain the possibility of vertical transmission. This study results indicated that SARS-CoV-2 was positive in $16(16.67 \%)$ out of 96 neonates at birth suggesting that there could be possibility of intrauterine fetal infection because of SARS-CoV-2 infection during the third trimester of pregnancy. This study findings are in agreement with 2 recent research letters reported on 3 neonates born to women with confirmed COVID-19 who tested positive for immunoglobulin $G$ and immunoglobulin $\mathrm{M}$ antibodies despite having a negative viral nucleic acid result, raising the possibility of vertical transmission, but more data are needed. ${ }^{20,21}$

There is controversy between guidance for delayed cord clamping, which is due to lack of evidence. Consensus 
guidance from China advises that 'delayed cord clamping is not recommended', in order to reduce the risk of vertical transmission, and that infants should be separated from mothers affected by COVID-19.22 Delayed cord clamping is not practiced in the study institute and the same was followed in deliveries of COVID-19 infected pregnant women. Interim guidance from ISUOG advises clinicians to consider not undertaking delayed cord clamping. ${ }^{23}$ RCOG guidance does not concur, advising that delayed cord clamping should be practiced as normal. It can be argued that further 1 min of perfusion from the placenta is highly unlikely to affect the risk of vertical transmission due to fact that there is already enough exposure to maternal secretions and blood during vaginal delivery. Infants may contract infection after delivery from their mothers through normal mode of transmission. All the neonates in this study were top-fed in NICU with expressed breastmilk. WHO guidelines states that 'the benefits of skin-to-skin contact and breastfeeding substantially outweigh the potential risks of transmission and illness associated with COVID-19 infection' while guidance from China states that 'Infants shouldn't be given feeding with the expressed breast milk from confirmed or suspected COVID-19 mothers'. ${ }^{24}$ Guidance from the Centres for Disease Control and Prevention is less clear but is still precautionary. ${ }^{8}$

\section{CONCLUSION}

In pregnancy, due to the physiological alterations in cardiovascular, respiratory and immune system, the pregnant women are at greater risk and vulnerable to become the victims of pathogens, especially in the case of outbreak like SARS-CoV-2. Currently, there is no evidence that pregnant women are at greater risk to succumb to COVID-19 infection and experience severe pneumonia. This preliminary study however does not rule out the possibility of vertical transmission of SARS-CoV2 when it manifests towards the end of pregnancy. This study does not report any increased risks of spontaneous abortion and spontaneous preterm deliveries.

Currently there is worldwide collection of clinical data and research with the aim to answer some of the questions in relation to the risk of teratogenicity, congenital infection, labour management and mode of delivery. Early data analysis regarding the pregnancy outcomes in COVID-19 are optimistic but due to the limited availability of study in the literature on this new disease in pregnancy and restricted sample size, there is worldwide need for systematic data collection and judicious follow-up of disease in pregnancy. This would lead us to evidence-based management, treatment and prevention of SARS-CoV-2 among pregnant population.

The life of health care professionals engaged in the battle against SARS-CoV-2 is equally important and adequate safety measures were ensured by using fully equipped PPE kits including N-95 masks.

\section{ACKNOWLEDGMENTS}

Authors would like to express their gratitude to medical superintendent, all faculty professors, post graduate resident colleagues and staff members in helping collect the data. Special acknowledgement to the IT department of our hospital for helping compiling information via ARCUS software.

\section{Funding: No funding sources Conflict of interest: None declared \\ Ethical approval: The study was approved by the Institutional Ethics Committee}

\section{REFERENCES}

1. Zhu N, Zhang D, Wang W, Li X, Yang B, Song J, et al. China novel coronavirus investigating and research team. A novel coronavirus from patients with pneumonia in China, 2019. N Engl J Med. 2020;382:727-33.

2. Weiss SR, Leibowitz JL. Coronavirus pathogenesis. Adv Virus Res. 2011;81:85-164.

3. Masters PS, Perlman S. Coronaviridae. In: Knipe DM, Howley PM, eds. Fields virology. $6^{\text {th }}$ ed. Lippincott Williams and Wilkins; 2013:825-858.

4. Su S, Wong G, Shi W, Liu J, Lai AC, Zhou J, et al. Epidemiology, genetic recombination, and pathogenesis of coronaviruses. Trends Microbiol. 2016;24:490-502.

5. Cui J, Li F, Shi ZL. Origin and evolution of pathogenic coronaviruses. Nat Rev Microbiol. 2019;17:181-92.

6. Chan JF, Kok KH, Zhu Z, Chu H, To KK, Yuan S, et al. Genomic characterization of the 2019 novel human-pathogenic coronavirus isolated from a patient with atypical pneumonia after visiting Wuhan. Emerg Microbes Infect. 2020;9:221-36.

7. Royal College of Obstetricians Gynaecologists, Royal College of Midwives. Coronavirus infection in pregnancy: Information for healthcare professionals. Available at: https://www.rcog.org.uk/global.... Published April 9, 2020. Accessed on $13^{\text {th }} 2020$.

8. Centers for Disease Control and Prevention. Coronavirus Disease (COVID-19). People who need extra precautions: Pregnancy and Breastfeeding. Available at: https://www.cdc.gov/coronaviru. Accessed on 13th April 2020.

9. World Health Organization. Laboratory testing for 2019 novel coronavirus (2019-nCoV) in suspected human cases. Interim guidance. Available at: https://www.who.int/publications-detail/laboratorytesting-for-2019-novel-coro-navirus-in-suspectedhuman-cases-20200117. Accessed on 24 ${ }^{\text {th }}$ March 2020.

10. Ministry of health and family welfare. Revised discharged policy, dated $8^{\text {th }}$ May, 2020. Available at: https://www.mohfw.gov.in/pdf/FAQsonRevisedDisc hargePolicy.pdf Accessed on $10^{\text {th }}$ June 2020. 
11. Guan WJ, Ni ZY, Hu Y, Liang WH, Ou CQ, He JX, et al. Clinical char-acteristics of coronavirus disease 2019 in China. N Engl J Med. 2020;382(18):170820.

12. $\mathrm{Wu} \mathrm{Z}$, McGoogan JM. Characteristics of and important lessons from the coronavirus disease 2019 (COVID-19) outbreak in China: summary of a report of 72314 cases from the Chinese center for disease control and prevention. JAMA. 2020;323(13):123942.

13. Chawla D, Chirla D, Dalwai S, Deorari AK, Ganatra A, Gandhi A, et al. Perinatal-neonatal management of COVID-19 infection-guidelines of the federation of obstetric and gynaecological societies of India (FOGSI), National neonatology forum of India (NNF), and Indian Academy of Pediatrics (IAP). Indian Pediatr. 2020;57(6):536-48.

14. Naccasha N, Gervasi MT, Chaiworapongsa T. Phenotypic and meta-bolic characteristics of monocytes and gran-ulocytes in normal pregnancy and maternal infection. Am J Obstet Gynecol. 2001;185:1118-23.

15. Alattar R, Ibrahim TBH, Shaar SH, Abdalla S, Shukri K, Daghfal JN, et al. Tocilizumab for the treatment of severe COVID-19. J Med Virol. 2020;18.

16. Madinger NE, Greenspoon JS, Ellrodt AG. Pneumonia during pregnancy: has modern technology improved maternal and fetal outcome? Am J Obstet Gynecol. 1989;161:657-62.

17. Chen YH, Keller J, Wang IT, Lin CC, Lin HC. Pneumonia and pregnancy outcomes: a nationwide population-based study. Am J Obstet Gynecol. 2012;207:288.e1-7.

18. Wong SF, Chow KM, Leung TN, Ng WF, Ng TK, Shek CC, et al. Pregnancy and perinatal outcomes of women with severe acute respiratory syndrome. Am J Obstet Gynecol. 2004;191:292-7.
19. Al Wattar B, Murugesu N, Tobias A, Zamora J, Khan KS. Management of first-trimester miscarriage: a systematic review and network meta-analysis. Hum Reprod Update. 2019;25:362-74.

20. Zeng $\mathrm{H}, \mathrm{Xu} \mathrm{C}$, Fan J, et al. Antibodies in in-fants born to mothers with COVID-19 pneumonia. JAMA. 2020;323(18):1848-9.

21. Dong L, Tian J, He S, Zhu C, Wang J, Liu C, et al. Possible vertical transmission of SARS-CoV-2 from an infected mother to her newborn. JAMA. 2020;323(18):1846-8.

22. Wang L, Shi Y, Xiao T, Fu J, Feng X, Mu D, et al. Working committee on perinatal and neonatal management for the prevention and control of the 2019 novel coronavirus infection. Chinese expert consensus on the perinatal and neonatal management for the prevention and control of the 2019 novel coronavirus infection (First edition). Ann Transl Med. 2020;8:1-8.

23. Poon LC, Yang H, Lee JCS, Copel JA, Leung TY, Zhang Y, et al. ISUOG Interim Guidance on 2019 novel coronavirus infection during pregnancy and puerperium: information for healthcare professionals. Ultrasound Obstet Gynecol. 2020;55:700-8.

24. World Health Organization. Frequently asked questions: Breastfeeding and COVID-19, dated $12^{\text {th }}$ May, 2020. Available at: https://www.who.int/docs/default-source/maternalhealth/faqs-breastfeeding-and-covid19.pdf?sfvrsn=d839e6c0_5. Accessed on $10^{\text {th }}$ June 2020.

Cite this article as: Shah PT, Shah SR, Shah SR, Yadav PA, Patel BS, Chudasama TJ. Fetomaternal outcome in COVID-19 infected pregnant women: a preliminary clinical study. Int J Reprod Contracept Obstet Gynecol 2020;9:3704-10. 